\title{
Bertahan untuk Hidup: Konvergensi Pers Cetak dalam Industri Digital Media
}

\author{
https://doi.org/10.25008/caraka.v1i1.40 \\ MULYONO SRI HUTOMO \\ Universitas Prof. Dr. Moestopo (Beragama), Indonesia
}

\begin{abstract}
Mass media industry particularly print media in Indonesia comes under heavy pressure to survive in the era of digital disruption. High printing costs, coupled with high distribution costs and employee salaries have caused difficulties for print media companies to maintain their businesses. Some print media companies have opted to shut down their businesses, while others have survived by making various efficient efforts and diversifying their businesses. The convergence of print media into digital media has offered an alternative to maintain print media as the management of Telaah Strategis magazine has done. This research aims to see the efforts made by the management of Telaah Strategis magazine to survive in the media industry in Indonesia. The results of this research show that Telaah Strategis magazine uses a variety of media convergence models to be able to maintain its task of disseminating information by transforming it into a news portal and digital magazine and appearing in the social media platform. In addition, it also markets its digital magazine at online product sale exchange.
\end{abstract}

Keywords: Media convergence; mass media; print media; digital industry;

\section{ABSTRAK}

Industri media massa khususnya pers cetak di Indonesia menghadapi tekanan berat untuk bertahan hidup di era disrupsi digital. Mahalnya ongkos cetak, dan tingginya biaya distribusi serta gaji karyawan membuat industri media massa cetak kesulitan dalam mempertahankan esksitensi usahanya. Sejumlah media cetak memilih menutup usaha dan sejumlah lainnya bertahan dengan melakukan berbagai upaya efisiensi dan diversifikasi usaha. Konvergensi pers cetak menjadi pers digital menjadi pilihan untuk mepertahankan eksistensi pers cetak, sebagaimana dilakukan pengelola majalah Telaah Strategis. Penelitian ini bertujuan untuk mengetahui upaya majalah Telaah Strategis mempertahankan eksistensinya untuk bertahan hidup dalam industri media di Indonesia. Hasil penelitian menunjukkan, majalah Telaah Strategis menggunakan berbagai model konvergensi media agar bisa mempertahankan tugasnya menyerbarluaskan informasi dengan bertransformasi menjadi portal berita dan majalah digital, serta tampil di platform media sosial. Selain itu memasarkan produk majalah digitalnya ke bursa penjualan produk daring.

Kata kunci: Konvergensi media; media massa; media cetak; industri digital;

\begin{tabular}{|l|}
\hline Mulyono Sri Hutomo (hutomo@std.moestopo.ac.id) \\
\hline Copyright @ 2020 (Mulyono Sri Hutomo) \\
Licensed under the Creative Commons Attribution-NonCommercial-ShareAlike 4.0 (CC BY-SA 4.0) \\
\hline Penulis menyatakan tidak mempunyai konflik kepentingan dalam penelitian dan penerbitan publikasi ini. \\
\hline Available at http://caraka.web.id \\
\hline Submitted: 21 April 2020, Revised: 29 May 2020, Accepted: 21 June 2020 \\
\hline
\end{tabular}




\section{PENDAHULUAN}

Industri media cetak di Indonesia mengalami masa-masa sulit sejak tahun 2015. Majalah musik Rolling Stone dan FHM Indonesia menerbitkan edisi terakhirnya. Sebelumnya, beberapa majalah tentang gaya hidup seperti Fitness for Men Indonesia, Auto Bild Indonesia, Esquire Indonesia, dan majalah Hai juga menghentikan penerbitannya.

Tidak hanya majalah, berbagai koran juga memutuskan menerbitkan edisi terakhirnya. Harian Bola milik Kompas Gramedia di akhir 2015, koran Jakarta Globe berhenti cetak juga pada 2015, Sinar Harapan tahun 2016, Koran Tempo edisi minggu, juga terhenti hidupnya. Selain itu ada pemutusan hubungan kerja massal di Harian Seputar Indonesia tahun 2017. Semua itu merupakan fakta tidak terbantahkan atas surutnya industri media cetak di Indonesia.

Paul Gillin, konsultan teknologi informasi dari Massachusetts menyatakan model bisnis media cetak tidak mungkin lagi bertahan hidup. Perkembangan ekonomi sedang bergerak melawan bisnis cetak. Media cetak melibatkan banyak karyawan, sehingga biaya produksi lebih mahal dari media online. Apalagi, zaman sekarang, generasi muda lebih suka mengakses internet daripada membeli majalah atau koran (Kusuma, 2016).

Internet membuka ruang publik untuk partisipasi warga, baik itu profesional atau amatir dalam diseminasi informasi. Informasi bukan lagi esklusif milik jurnalis dan media. Kerja-kerja jurnalistik kini juga dilakukan oleh publik. Inilah era yang disebut Alvin Toffler, futurolog 1980an sebagai era prosumsi (produksi dan konsumsi). Masyarakat bisa menjadi produsen sekaligus konsumen informasi.

Stephen J.A. Ward, guru besar etika jurnalistik Universitas Wisconsin Madison, dalam artikelnya, Digital Media Ethics, mencermati hadirnya internet membuat jurnalis profesional masa kini harus berbagi ruang dengan twitter, blogger, jurnalis warga, dan pengguna media sosial. Sejarah mencatat, media-media baru selalu hadir seiring dengan perkembangan teknologi .

Internet membuat umat manusia seperti hidup dalam sebuah kampung global. Internet sebagai medium juga telah mempengaruhi cara kita hidup, termasuk cara kita memproduksi dan mengonsumsi berita.

Perkembangan media online kini menjadi ancaman bagi koran dan media cetak. Pesatnya perkembangan internet telah mendorong masyarakat untuk mengakses media online secara mudah melalui handphone, atau gadget.

Media cetak mulai terancam keberadaannya, pembaca setia media cetak beralih ke media online. Realita tersebut mengancam penerbit media cetak. Namun media cetak memiliki karakter yang khas yaitu: berita yang jelas, lengkap dan terperinci, selain itu selama berabad-abad, media cetak telah mengiringi perkembangan peradaban manusia, sehingga tidak mudah dilupakan.

Pengguna internet di Indonesia, termasuk yang memanfaatkannya untuk membaca berita, menjadi salah satu penyebab mulai ditinggalkannya media massa cetak. Jumlah pembeli koran terus merosot dalam empat tahun terakhir karena masyarakat beranggapan bahwa informasi seharusnya bisa didapat secara gratis. Oleh karena itu, banyak upaya dilakukan oleh media cetak untuk mempertahankan hidupnya (Ritonga, dkk, 2017; Suraya, 2019).

Konvergensi newsroom, dalam konvergensi ini jurnalis yang berbeda platform, misalnya dari surat kabar, online, dan televisi menyatukan dirinya dalam satu ruang produksi berita. Mereka mengerjakan tugas sesuai dengan platform medianya. Konvergensi newsgathering, 
dalam menjalankan model ini, seorang jurnalis dituntut untuk mampu mencapai tingkatan multitasking.

Dengan melalui pelatihan atau training khusus, seorang jurnalis dituntut untuk dapat melakukan pekerjaan yang dilakukan oleh media dengan platform lain dalam satu grup. Misalnya, seorang wartawan cetak harus mampu membuat berita untuk cetak, online, dan sekaligus untuk televisi. Selain itu juga dituntut untuk mengambil foto atau video (Ritonga, 2007).

\section{METODE PENELITIAN}

Penelitian ini merupakan studi deskriptif dengan pendekatan kualitatif menggunakan data sekunder. Adapun paradigma penelitian yang digunakan adalah konstruktivis. Paradigma itu memberi kebebasan kepada peneliti untuk melakukan interpretasi terhadap data sesuai dengan konseptual yang ada dalam diri si peneliti.

Tujuan dari penelitian ini adalah untuk membuat deskripsi, gambaran atau lukisan secara sistematis, faktual dan akurat mengenai fakta-fakta, sifat-sifat serta hubungan antar fenomena yang diselidiki (Cresswell 2009; Sutopo 2006; Nazir 1988).

Teknik pengambilan informan melalui teknik purposive sampling yaitu pengambilan informan berdasarkan tujuan. Sedangkan teknik pengumpulan data dilakukan dengan wawancara, dokumentasi dan studi pustaka. Data dalam penelitian yang diperoleh dianalisis secara kualitatif.

Penelitian kualitatif menekankan pada makna, penalaran, definisi, suatu situasi tertentu (dalam konteks tertentu) lebih banyak meneliti hal-hal yang berhubungan dengan kehidupan sehari-hari. Pendekatan kualitatif lebih lanjut mementingkan proses dibandingkan hasil akhir. Oleh karena itu urutan-urutan kegiatan dapat berubah sewaktu-waktu tergantung pada kondisi dan banyak gejala-gejala yang ditemukan.

Penelitian ini bersifat deskriptif bertujuan untuk mengkritik kelemahan penelitian kuantitatif serta untuk menggambarkan, meringkaskan berbagai kondisi, situasi dan fenomena yang ada di masyarakat dan menjadi objek penelitian (Bungin 2013).

Selain itu penelitian deskriptif juga memberikan penggambaran tentang suatu fenomena atau penggambaran sejumlah fenomena secara terpisah-pisah. Dengan demikian, peneliti tidak akan memandang bahwa sesuatu itu adalah memang demikian keadaannya (Moleong, 2009).

Tujuan penelitian ini adalah untuk mengetahui bagaimana model konvergensi yang dilakukan majalah Telaah Strategis mempersiapkan platform digital untuk menghadapi media digital yang terus berkembang. Juga untuk mengetahui jenis platform digital yang dipilih sebagai konverensi konten dari majalah Telaah Strategis.

\section{HASIL PENELITIAN}

Media massa konvensional seperti halnya majalah cenderung satu arah sementara kebiasaan interaktif yang personal sudah menjadi tradisi. Interaktivitas komunikasi dengan media baru yang interaktif telah memungkinkan adopsi teknologi ini secara sosial.

Selain itu, manusia selalu ingin eksistensis politik, sosial, dan budayanya diketahui orang lain dengan mudah, dan itu dapat dipenuhi dipenuhi oleh fungsi-fungsi komunal interaktifitas yang disajikan media baru melalui komunikasi berjaringan dan interaktif.

Akibatnya, konsumsi satu arah yang diterapkan majalah telah berubah menjadi konsumsi terintegrasi pada diskusi kelompok sosial dan media massa, sehingga fungsi sosial 
ini terpenuhi oleh online, sedangkan majalah ditinggalkan sebagai prioritas pengambilan informasi.

Dengan begitu, majalah mulai ditinggalkan audience jika tidak terintegrasi dengan sistem informasi dan komunikasi yang dihubungkan pada jaringan sosial di iinternet. Majalah tetap akan dipakai sebagai sumber sekunder dari agenda setting dan sumber informasi di masyarakat. Konsumsi majalah yang lebih menyimbolkan kelas tertentu, akan menyulitkannya bersaing dengan media online.

Budaya baru dalam pemanfaatan waktu dihadirkan oleh media online. Konsumsi berita menggunakan media online kini tidak hanya pada waktu luang saja, namun juga pada jamjam penting atau pokok karena dimanfaatkan sebagai sarana untuk bekerja. Batasan waktu, ruang dan jangkauan menjadi hilang, sehingga gaungnya pun menjadi luas tanpa sekat-sekat seperti pada efek dari media konvensional.

Majalah Telaah Strategis terbit kali pertama tahun 1989 berdasarkan Surat Tanda Terdaftar (STT) No. 1433 SK/Ditjen PPG/STT/1989 tanggal 29 Juni 1989, dengan Nomor ISSN 0852-9663. Majalah ini, dimiliki sepenuhnya oleh Ikatan Keluarga Alumni Lembaga Ketahanan Nasional Indonesia (IKAL).

Tujuan penerbitan Majalah Telaah Strategis sebagai sarana penyebarluasan dan pengembangan pemikiran terutama yang menyangkut masalah-masalah strategis kehidupan berbangsa dan bernegara. Majalah Telaah Strategis dalam bentuk cetak terbit setiap tiga bulan.

Susunan pengelola majalah Telaah Strategis adalah Pemimpin Umum, Komisaris Jenderal Pol. (Purn) Drs. Togar M.; Wakil Pemimpin Umum, Ir. Bambang Sutrisno, IAI; Pemimpin Usaha, Dr. Nieta Hidayani, M.B.A, M.M; Wakil Pemimpin Usaha, Ir. Lucky Ali Moerfiqin, MM, MBA; Pemasaran Promosi dan Iklan, Sugiyanto Haryo Semangun, S.E, M.Sc, Jay Singgih; dan Bagian Keuangan, Masita.

Susunan Redaksi majalah Telaah Strategis adalah Pemimpin Redaksi, Dr. Rajab Ritonga, M.Si; Redaktur Pelaksana, Zackir L. Makmur, Nur Budi Hariyanto, M.Si dengan reporter dan koresponden dari berbagai daerah di Indonesia.

Majalah Telaah Strategis juga memiliki Dewan Redaksi yakni August Parengkuan, Laksda TNI Estu Prabowo, Laksda TNI (Purn) Soemindiharso, Dr. Djohari Lubis, Ir. Erina Tobing, M.Sc, Dr. Retno Intani ZA, M.Sc., Dra. Dwi Hernuningsih, M.Si., Dr. I.G.N. Arsana, SE, MM, PSC.

Alamat redaksi majalah Telaah Strategis adalah di Jl. Merdeka Selatan No. 10 Jakarta Pusat. Setidaknya, ada empat proses dasar yang dilakukan pemangku kepentingan majalah Telaah Strategis saat memutuskan konvergensi media dari cetak menjadi media online. Keempat proses tersebut adalah: (1) Menetapkan platform yang akan dipakai berdasarkan misi dan visi program yang telah ditetapkan; (2) Menaksir biaya awal produksi yang timbul; (3) Menaksir keuntungan dan memperhitungan dampak risiko yang timbul saat dilakukan peralihan media; (4) Pelaksanaan distribusi secara berkala artikel, foto, dan grafis pada platform yang telah ditetapkan sebelumnya.

\section{Portal Berita}

Melalui portal berita, batasan waktu, ruang dan jangkauan menjadi hilang, sehingga gaungnya pun menjadi luas tanpa sekat-sekat seperti pada efek dari media konvensional seperti media halnya koran dan majalah.

Menurut penjelasan informan 1, keputusan terbit dalam bentuk online merupakan pilihan tepat untuk menyebarluaskan berita secara cepat, efisien, dan murah dibandingkan dengan mencetaknya. Versi cetak tetap dipertahankan. Isinya berupa kajian ataupun telaah 
terhadap suatu persoalan strategis. Konten seperti itu merupakan ciri khas Telaah Strategis selama ini.

Pengelola majalah Telaah Strategis menggunakan WordPress sebagai mesin content managemen system portal berita. Portal berita majalah Telaah Strategis dapat diakses menggunakan alamat url https://telstrat.online.

WordPress adalah mesin content management system portal berita yang dibuat dan diluncurkan pada tahun 2003 oleh Matt Mullenweg dan Mike Little. Dalam lingkup bisnis, WordPress dikelola oleh perusahaan berbadan hukum yang bernama Automattic.

Content management system WordPers memungkinkan jurnalis mengirimkan berita, fotografer mengunggah foto berita, editor melakukan penyuntingan dan redaktur pelaksana mempublikasikan artikel secara online dan mengunggah gambar, dan sistem yang kemudian akan menyimpan berbagai unggahan dalam kode dan file yang disimpan dalam sebuah basis data.

Sementara itu media sosial mulai dikenal tahun 1978, saat sistem papan buletin atau bulletin board system (BBS) ditemukan oleh Ward Christensen dan Randy Suess. Sistem papan ini memungkinkan pengguna (user) bisa berhubungan dengan orang lain memakai surat elektronik atau pun mengunggah dan mengunduh melalui perangkat lunak yang tersedia saat itu.

BBS merupakan awal sebuah komunitas virtual dalam lingkup terbatas. Kala itu konektivitas internet berlangsung menggunakan saluran telepon yang terhubung dengan modem.

Kemunculan sejumlah situs jejaring sosial itu pada intinya bermula dari adanya inisiatif untuk menghubungkan orang-orang dari berbagai latar belakang yang ada di seluruh belahan bumi.

Sekitar 26 tahun kemudian, media sosial BBS tergantikan oleh Facebook. Media sosial Facebook didirikan oleh Mark Zuckerberg bersama beberapa teman kuliahnya di Universitas Harvard, yaitu Eduardo Saverin, Andrew McCollum, Dustin Moskovitz dan Chris Hughes, pada 4 Februari 2004.

Pada awalnya, Facebook hanya digunakan untuk kalangan terbatas di lingkungan kampus saja. Namun dengan cepat meluas ke wilayah Boston, Amerika Serikat, hingga mendunia, termasuk Indonesia (Wilson, 2012).

Facebook memungkinkan penggunanya berbagai unggahan dalam bentuk teks, foto, berkas lampiran dan video. Tak hanya Facebook, YouTube menjadi media sosial berbagi video.

YouTube adalah situs berbagi video yang berkantor pusat di San Bruno, California, Amerika Serikat. YouTube didirikan oleh Chad Hurley, Steve Chen dan Jawed Karim, yang ketiganya adalah mantan karyawan PayPal, situs jual beli online.

Sebelumnya, Chen dan Karim memang berasal dari kampus yang sama, yakni University of Illinois di Urbana Champaign. Sedangkan Hurley, kuliah di Indiana University of Pennsylvania, Amerika Serikat. Mereka mendirikan YouTube pada Februari 2005, tetapi baru berjalan setahun, situs itu telah dibeli oleh raksasa penjelajah dunia maya, Google Inc, pada akhir 2006.

Selain Facebook dan YouTube, media sosial populer lainnya adalah Instagram. Berbeda dengan dua media sosial pendahulunya, Instagram hanya bisa dijalankan pada peranti gawai seperti smartphone yang berbentuk aplikasi perankat lunak. 
Aplikasi ini adalah jaringan sosial berbagi foto dan video seperti program-program lainnya. Hanya saja, yang paling membedakan adalah, tampilan foto Instagram memiliki ciri khas dengan bingkai persegi.

Instagram diciptakan oleh Kevin Systrom dan Mike Krieger dan diluncurkan pada Oktober 2010. Nama Instagram, menurut mereka, merupakan gabungan dari 'instant camera' dan 'telegram'. Instagram dapat dipasang pada beragam sistem operasi gawai dan diunduh dari Apple App Store, Google Play dan Windows Phone Store.

Dalam perkembangan lebih lanjut, media sosial kini menjadi sarana atau aktivitas yang masuk kategori digital marketing, karena banyak dijejali kemasan dan muatan pemasaran.

Salah satu unsur mendasar yang ada pada situs-situs media sosial tersebut adalah fungsi dan layanan jejaring sosial. Layanan jejaring sosial memberikan jasa konektivitas melalui situs, platform dan sarana yang berfungsi memfasilitasi pembentukan jaringan atau hubungan sosial di antara beragam orang yang mempunyai ketertarikan, minat, kegiatan, latar belakang, maksud, kepentingan, tujuan, atau korelasi dunia nyata yang sama.

Pengelola Majalah Telaah Strategis menggunakan tiga platform media sosial yakni Facebook Page dengan alamat uniform resource locator (url) https://www.facebook.com/telaahstrategis/, Instagram dengan nama akun @telaahstrategis dengan alamat url https://www.instagram.com/telaahstrategis/, dan media sosial berbagai video YouTube dengan nama akun Telaah Strategis dengan alamat url https://www.youtube.com/channel/UCJLiyfNxqC2h2SR1kT85YOw.

\section{Majalah Digital Melalui Google Play Book}

Google Play Book merupakan produk dari perusahaan Google Inc, yang berkekhususan pada jasa dan produk Internet. Produk-produk tersebut meliputi teknologi pencarian, komputasi awan, perangkat lunak, dan periklanan.

Google Inc dikelola oleh Alphabet Inc, yang juga mengelola perusahaan Calico, Google Ventures, Google Capital, Google X, dan Nest Labs. Google Play Book memiliki memiliki tempat utama bisnis di 1600 Amphitheatre Parkway, Mountain View, Amerika Serikat. Selain itu, juga memiliki alamat bisnis lain di Dublin, Irlandia.

Dalam kesepakatannya dengan Google Inc, pengelola majalah Telaah Strategis yang dalam kesepakatan ini disebut sebagai penerbit, memberikan salinan digital dari suatu judul resmi yang dipilih agar dapat diakses untuk dijual kepada pengguna akhir berdasarkan perjanjian. Google Play Buku akan mencakup semua konten penerbit dalam judul resmi yang terkait.

Konten penerbit berarti semua konten yang terkandung dalam judul resmi, termasuk tetapi tidak terbatas pada semua teks, gambar, foto, ilustrasi, materi, dan karya seni yang terkandung baik dalam Judul Resmi maupun pada setiap jaket dan sampul.

Dalam kesepakatan antara pengelola Majalah Telaah Strategis dengan Google, penerbit akan menyerahkan judul resmi kepada Google (atau Perusahaan Google Group yang ditunjuk oleh Google) dalam format digital yang disetujui oleh Google. Penerbit akan menyerahkan judul resmi tahap pertama kepada Google dalam waktu 30 hari sejak tanggal efektif.

Semua penyerahan judul resmi dilakukan sesuai dengan petunjuk Google, sebagaimana diberitahukan kepada penerbit dari waktu ke waktu dan dengan biaya yang ditanggung oleh penerbit. Penerbit juga akan memberikan dukungan teknis, secara cuma-cuma, sebagaimana yang diperlukan secara wajar untuk mentransfer judul resmi apa pun. 
Penerbit menyetujui bahwa Google mengandalkan informasi harga Google Play Book yang diberikan oleh penerbit untuk memastikan bahwa majalah digital tersebut dijual dengan harga yang sesuai dengan peraturan harga tetap yang berlaku.

Penerbit menggunakan fitur yang disediakan oleh Google dalam Akun Penerbit sebagaimana yang mungkin diperbarui dari waktu ke waktu atau metode lain apa pun yang disepakati antara para pihak untuk mengomunikasikan harga akhir tetap majalah digital dan informasi terkait setiap Google Play Book kepada Google dalam mata uang wilayah diseluruh dunia.

Untuk majalah digital yang dijual melalui layanan Google Play Buku, disekati bagi hasil penjualan sebesar 52 berbanding 48 persen. Perusahaan Google Group akan membayarkan kepada penerbit 52 persen dari harga jual atau harga akhir tetap majalah digital sebagaimana berlaku untuk penjualan wilayah diseluruh dunia menggunakan mata uang yang disepakati sebelumnya.

Google memberi pengelola majalah Telaah Strategis akses ke laporan penjualan Google Play Book dalam format yang secara umum disediakan kepada penerbit lainnya. Informasi selengkapnya tentang data yang disediakan perusahaan Google Group dapat diakses setiap waktu yang dipilih rentang tanggalnya melalui akes Internet.

Majalah Telaah Strategis Edisi 139 menjadi edisi digital perdana yang didistribusikan melalui Google Playbook pada 14 Mei 2019. Majalah tersebut dapat diakses melalui tautan url https://books.google.co.id/books?id=N6qXDwAAQBAJ. Majalah digital ini didistribusikan tanpa mengurangi halaman edisi cetak, yakni 52 halaman berwarna.

\section{KESIMPULAN}

Konvergensi media yang dilakukan majalah Telaah Strategis melalui website portal berita, unggahan konten di media sosial dan edisi majalah elektronik melalui Google Play Book merupakan jawaban atas tuntutan eksistensi industri media di era digital.

Konvergensi media adalah suatu keharusan agar mampu bersaing di tengah agresifnya era media digital saat ini. Media cetak harus mempersiapkan berbagai platform untuk terus mempertahankan eksistensi merk, mempertahankan kelangsungan visi misi penerbitan dan memperoleh keuntungan agar usaha penerbitan terus berlangsung.

Kerjasama dengan perusahaan lain menjadi perlu agar bersinergi dengan baik untuk berbagi model usaha. Pengelola majalah Telaah Strategis menunjukkan kemampuan untuk bekerjasama dengan perusahaan internasional Google dalam penerbitan edisi digital. Kerjasama perlu untuk saling melengkapi teknologi, artikel, foto dan video yang tidak dimiliki satu perusahaan dengan yang lain untuk mendukung konvergensi media. Keberlangsungan entitas majalah cetak menjadi fokus yang terus menerus dilakukan oleh awak redaksi, dewan redaksi dan pengelola usaha media cetak.

\section{REFERENSI}

Bungin, B. (2013). Metodologi Penelitian Kualitatif (Cetakan ke 6). Jakarta: PT. Raja Grafindo Persada

Cresswell, J.W. (2009). Research Design: Pendekatan Kualitatif, Kuantitatif and Mixed. Edisi Ketiga. Yogyakarta: Pustaka Pelajar. 
Moleong, L. J.(2009). Metodologi Penelitian Kualitatif. Bandung: PT. Remaja Rosdakarya Nazir, M. (1988). Metode Penelitian. Jakarta: Ghalia.

Kusuma, S. (2016). Posisi Media Cetak di Tengah Perkembangan Media Online di Indonesia. Jurnal InterAct, 5(1): 56-71.

Putri, C.E \& Hamzah, R.E. (2018). Konvergensi Konten Majalah Popular dalam Industri Digital Media Cetak. Warta Ikatan Sarjana Komunikasi Indonesia, 1(1): 28-39.

Ritonga, R. (2007). Reposisi Ekonomi Politik Kantor Berita di Era Konvergensi Media: Studi Komodifikasi Informasi di Newsroom Kantor Berita Nasional dan Kantor Berita Internasional. Disertasi. Universitas Indonesia.

Ritonga, R., Murwani, E \& Ritonga, S. (2017). Gender Awareness of Maria Hartiningsih as Daily Kompas Reporter. Jurnal Komunikasi Ikatan Sarjana Komunikasi Indonesia, 2(2): 82-91.

Suraya, S. (2019). Journalist Credibility Based on Digital Media Used, Jurnal Komunikasi Ikatan Sarjana Komunikasi Indonesia, 4(1), 26-34.

Sutopo, HB. 2006. Metodologi Penelitian Kualitatif Dasar Teori dan Terapannya Dalam Penelitian, Surakarta: Universitas Sebelas Maret Press.

Wilson, Robert E., Samuel D. Gosling, Lindsay T. Graham (2012). A Review of Facebook Research in the Social Sciences. Journal Perspectives on Psychological Science, (7): 203. 